\title{
La urodinámica "In vitro"
}

\author{
Bustamante Alarma S, Carballido Rodríguez J.
}

Servicio de Urología. Hospital Universitario Puerta de Hierro. Universidad Autónoma. Madrid.

Actas Urol Esp. 2008;32(2):169-171

$\mathrm{L}$ a Urodinámica estudia la actividad del tramo urinario inferior (vejiga y uretra) en sus 2 fases: de llenado y de vaciado vesical, asimismo puede ser realizada de 2 formas: convencional o con monitor externo ${ }^{1}$. En la práctica diaria es una herramienta de trabajo de indudable valor, para alcanzar un conocimiento más amplio de la fisiología miccional y de esta manera contribuir al diagnóstico y seguimiento de múltiples patologías de localización en órganos genitourinarios

En términos de desarrollo de política científica, una cultura poco propicia en nuestro medio, a lo largo de muchos años nos ha conducido a un distanciamiento ostensible y poco aconsejable, a lo largo de toda la trayectoria profesional y desde los estudios de pregrado se recibe la enseñanza clásica en materia clínica, y a su vez, se proporciona una educación y un interés por la investigación básica. Afortunadamente el proceso de convergencia con los principales países de nuestro entorno está modificando ese panorama y aunque la velocidad de este proceso todavía no es suficiente, lo cierto es que se desarrolla la investigación están cada vez más próximos y las expectativas en torno a la política de I+D son cada vez más elevadas.

La "investigación traslacional" concibe la investigación biomédica desde la perspectiva de la agrupación y unificación de todos los profesionales implicados en una determinada investigación en sus diferentes niveles y cuyo objetivo final es el beneficio del paciente, se trata de una investigación con predominio "de grupo". La implicación de profesionales en este modelo de investigación es independiente de que se realice físicamente en la entrevista médico-paciente, en el diseño y metodología elegida, o en el laboratorio con modelos animales o humanos. Se trata, por tanto, de equipos multidisciplinarios en toda regla. La Urología, obviamente, no es ajena a esta realidad científica y debe favorecerse de ella ${ }^{2}$. La investigación Urodinámica efectuada con criterios de investigación traslacional es, en este sentido, paradigmática ya que la prevalencia, incidencia creciente y repercusión socio sanitaria de las patologías en cuya metodología diagnóstica y manejo terapéutico se incluyen estas exploraciones funcionales son cada vez más significativas.

En nuestro Servicio, conscientes de esta realidad, una de las líneas de investigación, verdadera apuesta por la investigación traslacional, se lleva a cabo con modelos urodinamicos desarrollados en el laboratorio, en colaboración con el Departamento de Fisiología de la Facultad de Farmacia de la Universidad Complutense de Madrid (UCM). La metodología y los resultados de estos estudios ${ }^{3,4}$, ofrecen un extraordinario paralelismo con los estudios efectuados "in vivo" y acuñamos toda la actividad de esta línea de investigación con el término Urodinámica "in Vitro."

En el caso de los estudios funcionales efectuados en el laboratorio, el objetivo es reproducir con la mayor fiabilidad posible, el comportamiento de determinadas preparaciones en su medio natural y ante un determinado estímulo. En el caso del sistema genitourinario se utilizan preparaciones (uréter, vejiga, cuello vesical, uretra...) de diversos modelos experimentales como son (cerdo, cordero, caballo y humano) procedente del animal de experimentación y que se obtiene en el matadero municipal, inmediatamente después del sacrificio del animal. Este material se transporta hasta el laboratorio en termos a temperatura de $37^{\circ}$ y oportuno soporte nutricial (liquido de Krebs), es decir, en las mejores condiciones fisiológicas posibles. Una vez en el Laboratorio, las muestras son depositadas en placas de Petri con líquido nutricio y se disecan, a punta de tijera con la menor manipulación posible (Fig. 1). 


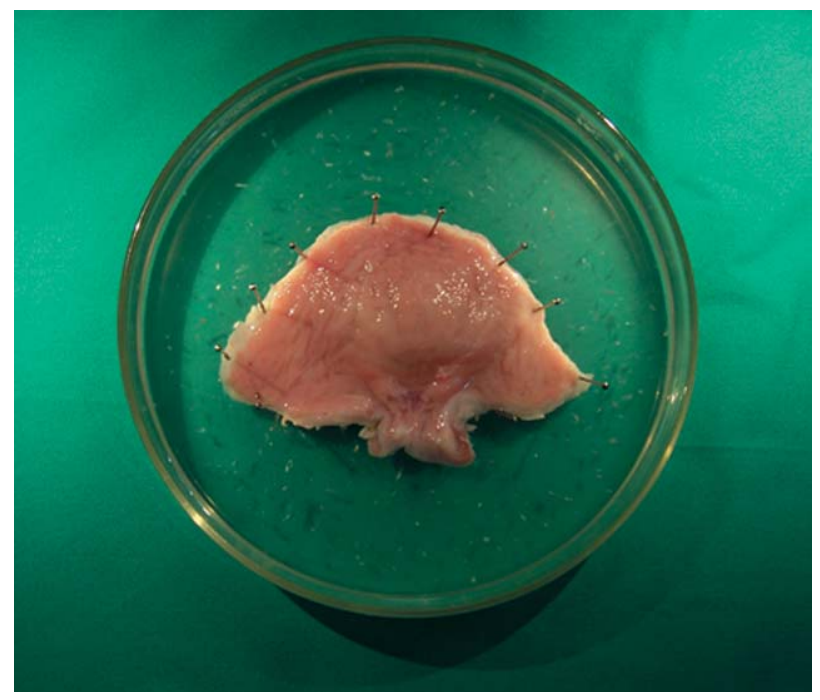

FIGURA 1

Posteriormente son sumergidas en baño de órganos de $5 \mathrm{ml}$ de capacidad, donde uno de sus extremos se conecta a un tornillo de desplazamiento y el otro a un transductor que transforma la señal mecánica en eléctrica, posteriormente se amplifica y finalmente se registra. A las preparaciones, se les proporciona una tensión idónea. A continuación, se comprueba su viabilidad incubándolas en una solución de Krebs enriquecida en $\mathrm{K}^{+}(124 \mathrm{Mm})$ y se inicia el estudio estimulándolas con diferentes sustancias (estimulación exógena) ó estimulación eléctrica transmural (colocación de 2 electrodos de platino a ambos lados de las muestras) (Fig. 2).

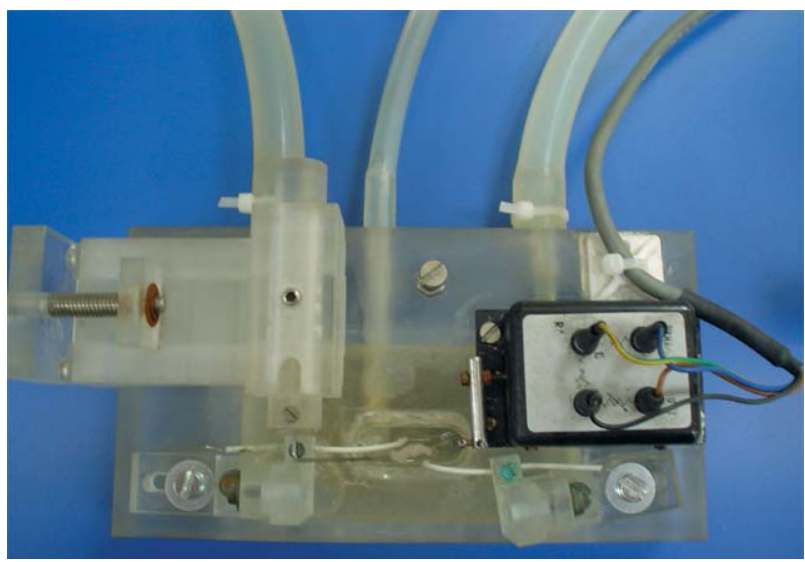

FIGURA 2

El análisis detallado de esta metodología experimental nos permite observar la gran similitud que existe entre la Urodinámica convencional "in vivo" y la que denominamos en este comentario editorial Urodinámica realizada en el laboratorio "in vitro".

La complementariedad de la investigación y su carácter traslacional a las condiciones fisiológicas en humanos de estos estudios urodinamicos se concreta en la metodología, transductores utilizados, parámetros de evaluación de la respuesta miccional, papel de los neurotransmisores y modelos de registro (Tabla 1 ).

Definitivamente, la metodología empleada en el desarrollo de esta línea de investigación nos parece un ejemplo representativo del carácter tralacional que debe presidir la investigación uro-

Tabla 1

\begin{tabular}{|c|c|c|}
\hline Urodinámica & "in vivo" & "in vitro" \\
\hline Material & "In vivo" & "In vitro" \\
\hline Método & Determinaciones Presiones & Determinaciones Tensiones \\
\hline Utilización transductores & SI & $\mathrm{SI}$ \\
\hline Material & $\begin{array}{l}\text { Pacientes con patología susceptible } \\
\text { de estudio mediante evaluación } \\
\text { urodinámica }\end{array}$ & $\begin{array}{l}\text { Preparaciones en las mejores } \\
\text { condiciones fisiológicas y obtenidas } \\
\text { de modelos experimentales }\end{array}$ \\
\hline Respuesta miccional ante estímulos & $\begin{array}{l}\text { - Estimulación raíces sacras, } \\
\text { neuromodulación } \\
\text { - Lavados endovesicales (test agua } \\
\text { helada, ácido hialuronico, capsaicina } \\
\text { y resinferatóxina (entre otros) }\end{array}$ & $\begin{array}{l}\text { Estimulación de los nervios } \\
\text { intramurales con frecuencias entre } \\
1 \text { Herzio - } 32 \text { Hertzios }\end{array}$ \\
\hline $\begin{array}{l}\text { Efecto de diferentes sustancias } \\
\text { (agonistas y antagonistas) }\end{array}$ & Drogas (oxibutinina, tolterodina etc.) & $\begin{array}{l}\text { Incubación en el baño con diferentes } \\
\text { sustancias (ACh, NA, NO, atropina etc. }\end{array}$ \\
\hline Inscripción & Curvas de presiones (Pv,Pabd y $\mathrm{Pd})$ & Registros de respuesta \\
\hline
\end{tabular}


dinámica en Urología en un momento de expansión y desarrollo farmacológico relevante para el tratamiento de múltiples patologías de la unidad funcional vesico-prostática. Nuestro objetivo no es otro que el de estímulo para el desarrollo de iniciativas de investigación en nuestra especialidad basadas en modelos en los que coexista cooperación entre profesionales y decisiones en política de desarrollo científico integradas en programas, nacionales y/o en el marco europeo, de gran responsabilidad haciendo la investigación urológica traslacional.

\section{REFERENCIAS}

1. Bustamante Alarma, S. Estructura y Función del Tracto urinario Inferior. Cirugia Funcional del Tracto Urinario Inferior. 2003; Cap 1, Págs. 15-22.
2. Carballido J. Investigación traslacional en Urología. Arch. Esp.Urol. 2004;56(6):681-684.

3. Bustamante S, Orensanz LM, Barahona MV, Contreras J, García-Sacristán A, Hernández M. Tachykininergic excitatory neurotransmission in the pig intravesical ureter. J Urol. 2000;164(4):1371-1375.

4. Bustamante S, Orensanz LM; Barahona MV, García-Sacristán A, Hernández M. NK2 tachykinin receptors mediate contraction of the pig intravesical ureter: tachykinin-induced enhancement -non-cholinergic excitatoryu neurotransmission. Neurourol Urodyn. 2001;20(3):297-308.

Correspondencia autor: Dr. S. Bustamante Alarma Servicio de Urología

Hospital Universitario Puerta de Hierro

San Martín de Porres, 4 - 28035 Madrid

Tel.: 913368000

E-mail autor: bustamantealarma@yahoo.es

Información artículo: Editorial 